NBER WORKING PAPER SERIES

\title{
HOW DO DOCTORS BEHAVE WHEN SOME (BUT NOT ALL) \\ OF THEIR PATIENTS ARE IN MANAGED CARE?
}

\author{
Sherry Glied \\ Joshua Zivin \\ Working Paper 7907 \\ http://www.nber.org/papers/w7907
NATIONAL BUREAU OF ECONOMIC RESEARCH
1050 Massachusetts Avenue
Cambridge, MA 02138
September 2000

\begin{abstract}
The authors would like to thank seminar participants at the New York Federal Reserve Bank, Cornell University, Columbia University, and the Mount Sinai School of Medicine for many helpful comments. The views expressed are those of the authors and not necessarily those of the National Bureau of Economic Research.

(C) 2000 by Sherry Glied and Joshua Zivin. All rights reserved. Short sections of text, not to exceed two paragraphs, may be quoted without explicit permission provided that full credit, including $\subset$ notice, is given to the source.
\end{abstract}


How Do Doctors Behave When Some (But Not All)

of Their Patients are in Managed Care?

Sherry Glied and Joshua Zivin

NBER Working Paper No. 7907

September 2000

JEL No. I1

$\underline{\text { ABSTRACT }}$

Most physicians today treat a variety of patients within their practices and operate in markets where a variety of insurance arrangements co-exist. In this paper, we propose several theoretical explanations for physician treatment patterns when the patient population is heterogeneous at the practice and market level. Data from the 1993-1996 National Ambulatory Medical Care Survey (NAMCS) are used to test how practice-level and market-level HMO penetration affect treatment intensity. Practice composition has strong effects on treatment. HMO-dominated practices have shorter, but otherwise more treatment intensive visits than do other practices. Market characteristics are less important determinants of treatment. As HMO practice share rises, the differences between the treatment of non-HMO and HMO patients are attenuated. These results provide strong evidence for a model of physician behavior with fixed costs of effort in the form of visit duration. For tests ordered, medications prescribed, and return visits specified, the empirical evidence supports a model with marginal cost pricing for excess capacity. HMO and non-HMO treatment patterns are most distinct at the level of the practice, not the patient. HMO-dominated practices appear to use a practice style that is quite different from that used in other practices. These findings suggest that practices are likely to become more segregated over time.

\section{Sherry Glied}

Division of Health Policy and Management Joseph Mailman School of Public Health Columbia University

600 West $168^{\text {th }}$ St., $6^{\text {th }}$ Floor

New York, NY 10032

and NBER

sag1@,columbia.edu
Joshua Zivin

Division of Health Policy and Management Joseph Mailman School of Public Health Columbia University

600 West $168^{\text {th }}$ St., $6^{\text {th }}$ Floor

New York, NY 10032

jz126@columbia.edu 


\section{Physician Practice in a Mixed Payment Environment}

The past decade has seen managed care praised as a means to reduce the over-provision of health care pervasive in fee-for-service operations, and harshly criticized as a mechanism that leads to the under-provision of care. Yet, surprisingly, empirical studies of managed care typically find modest effects of managed care on the behavior of physicians in office practice (Miller and Luft, 1994). ${ }^{1}$ One possible explanation for the discrepancy between predictions and results is that while the incentives for treating an individual patient in isolation are clear, most patients are seen in a much more complicated context.

Physician practices are rarely comprised of entirely managed care patients.

Indeed, most physicians today see a range of patients whose insurers pay providers using a variety of payment levels and methods. Remler et al. (1997) surveyed 2000 physicians and found that the mean physician practice received capitation payments for about $13 \%$ of all patients, and $41 \%$ of all practices included at least some capitated patients. This situation is further complicated by heterogeneous treatment patterns across regions of the country, suggesting that perhaps the behavior of individual physicians are strongly influenced by the practices of physicians around them. These heterogeneous conditions may help explain the relatively modest impact managed care appears to have had on physician office practice.

In this paper, we propose several distinct theoretical models of patient treatment in a heterogeneous environment. At the practice level, we propose three models of

\footnotetext{
${ }^{1}$ There is, however, strong evidence that managed care organizations reduce the frequency of hospital admissions and the length of hospital stay.
} 
physician behavior: one in which there are fixed costs associated with different types of effort production; one in which physicians induce demand for services; and one in which managed care organizations pay marginal costs for excess physician capacity. In an environment with two types of practices, traditional fee-for-service and managed care, these three models yield distinct results about the behavior of physicians toward patients who pay with each of these types of coverage. The first and last imply a convergence in treatment intensity as managed care penetration in a practice increases, although the former suggests convergence to an intermediate level of intensity while the latter suggests convergence to the traditional fee-for-service intensity level. The second model suggests a divergence in effort intensity. At the regional, or market, level, we propose two models. In the first market-level model, we posit that physicians that treat managed care patients may need to attract them away from traditional fee-for-service practices. In this model, as the regional presence of managed care expands, effort intensity for traditional fee-for-service and managed care patients diverges. In the second model, managed care organizations enroll the healthiest patients. The role of managed care expansion on effort intensity is unclear and will depend on the manner in which patients are distributed across practices. Because physician effort can take many forms, a different model may best describe each type of effort.

These five theoretical hypotheses are tested using data from the National Ambulatory Medical Care Survey, an annual nationally representative survey of randomly sampled physicians in office-based practice. We find that at an individual patient level, treatment intensity is indeed lower under managed care, although managed care patients are more likely to have a return visit specified by their physician. Practice 
composition is shown to have a large and statistically significant effect on practice intensity. As the percentage of managed care patients in a practice increases, treatment intensities converge. In the case of tests ordered, medications prescribed, and return visits specified, effort to managed care patients increases and effort to fee-for-service patients remains constant, providing strong evidence for a model with marginal cost pricing for excess capacity. This result is slightly different for visit duration, where the form of convergence in treatment intensity provides strong evidence for a model with fixed costs of effort. The effects of market characteristics on physician behavior are insignificant. Further, our analysis suggests that other researchers that find significant market effects may, in fact, be observing omitted practice composition effects instead.

The paper is structured as follows. The next section presents the five theoretical models for physician behavior in a mixed payment environment. The first three models examine within practice heterogeneity; the last two examine across practice (regional) heterogeneity. Section three describes the data used in this paper. Section four provides empirical results and the final section concludes.

\section{Models of Physician Behavior in a Mixed Payment Environment}

Economic theory suggests that, holding all else equal, patients who pay using capitation rates or who visit salaried physicians will receive less intense services than those who pay using fee-for-service rates. The simple economics of capitation, salary, and fee-for-service payment, however, provide no guidance about how these alternative payment mechanisms might be affected by the behavior of other patients or other

practices. The industry literature on physician and hospital practice has begun to explore 
the problems of management in a mixed payment system, but this literature is very limited (Krohn and Broffman, 1998; Manheim and Feinglass, 1994). In the economics literature, most analyses of economies of scope contemplate the sale of two related products using similar pricing strategies, not two (nearly) identical products using different pricing strategies.

In the remainder of this section, we propose several theoretical models of physician management in a mixed payment system. These models focus on the sensitivity of treatment patterns by payment type to both practice and market compositions. For ease of exposition, we develop a very general model specification that encompasses all features of our proposed theoretical models. It is important to note that our principal choice variable, physician effort, is, in practice, multidimensional. Thus, different theoretical models may best describe different forms of effort (e.g. tests, medications, visit duration). The analysis of the general model specification is followed by a discussion of each of our five proposed models for physician behavior in a mixed payment system.

Consider a physician whose practice consists of two types of patients: fee-forservice patients, denoted by $f$; and managed care patients, who throughout the remainder of the theory section we will refer to as HMO patients, denoted by $h$. Given HMO goals to limit excessive treatment intensity, the implicit price the physician receives for each service rendered to an HMO patient, $p_{h}$, is less than the price received for each identical service rendered to a fee-for-service patient, $p_{f}$. We recognize that capitated and salaried physicians do not receive an explicit fee per service. Nonetheless, their income does depend (albeit indirectly) on providing services to their patients, i.e. certain levels of 
quality must be maintained to retain patients. For modeling purposes, we treat this return as a price. Let $\alpha$ represent the fraction of patients in managed care within a given practice, $\alpha_{j}$ represent the fraction of patients in managed care within a given market, $q_{f}$ and $q_{h}$ represent the production functions for quantity of services per patient, and $c_{f}$ and $c_{h}$ represent cost functions for physician services. The physician will choose a level of effort for each type of patient, $e_{f}$ and $e_{h}$, such that the combined profits from fee-forservice and HMO patients are maximized.

Formally, the physician's objective is represented by the following maximization problem:

(1) $\max _{e_{f} \cdot e_{h}} \alpha p_{h}(\alpha) q_{h}\left(e_{h}, \alpha\right)+(1-\alpha) p_{f} q_{f}\left(e_{f}, \alpha\right)-\alpha c_{h}\left(e_{h}, \alpha\right)-(1-\alpha) c_{f}\left(e_{f}, \alpha\right)$

The production of services is assumed to increase with effort, but at a decreasing rate, i.e., $q^{\prime}(e)>0$ and $q^{\prime \prime}(e)<0$, where primes denote differentiation. The costs of effort are assumed to increase with effort at an increasing rate, $c$ ' $(e)>0$ and $c$ ' $(e)>0$. The impacts of $\alpha$ and $\alpha_{j}$ on the price of services, the production of services, and the cost of effort will be addressed in the discussion of individual models.

The first-order conditions for the profit maximization specified in equation (1) are:

(2) $(1-\alpha) p_{f} \frac{\partial q_{f}}{\partial e_{f}}-(1-\alpha) \frac{\partial c_{f}}{\partial e_{f}}=0$

(3) $\alpha p_{h} \frac{\partial q_{h}}{\partial e_{h}}-\alpha \frac{\partial c_{h}}{\partial e_{h}}=0$

These equations simply state that the value marginal product of effort for each type of patient should equal the marginal cost of that effort. In other words, the marginal benefit 
the physician receives from his/her effort in the form of increased profits should equal the marginal cost of that effort. Given our assumptions about the production and cost functions specified above, the sign of the Hessian matrix of second-order conditions ensures a maximum.

As noted earlier, we are interested in the effects of changing physician practice composition (or regional practice composition) on physician effort levels. These comparative statics are obtained by totally differentiating (2) and (3) above and applying Cramer's rule. This yields the following conditions:

(4) $\frac{d e_{f}}{d \alpha}=\frac{\left(p_{f} \frac{\partial q_{f}}{\partial e_{f}}-\frac{\partial c_{f}}{\partial e_{f}}\right)+(1-\alpha)\left[\frac{\partial^{2} c_{f}}{\partial e_{f} \partial \alpha}-p_{f} \frac{\partial^{2} q_{f}}{\partial e_{f} \partial \alpha}\right]}{(1-\alpha) p_{f} \frac{\partial^{2} q_{f}}{\partial e_{f}^{2}}-(1-\alpha) \frac{\partial^{2} c_{f}}{\partial e_{f}^{2}}}$

(5) $\frac{d e_{h}}{d \alpha}=\frac{\left(-p_{h} \frac{\partial q_{h}}{\partial e_{h}}+\frac{\partial c_{h}}{\partial e_{h}}\right)+\alpha\left[\frac{\partial^{2} c_{h}}{\partial e_{h} \partial \alpha}-\frac{\partial p_{h}}{\partial \alpha} \frac{\partial q_{h}}{\partial e_{h}}\right]}{\alpha p_{h} \frac{\partial^{2} q_{h}}{\partial e_{h}^{2}}-\alpha \frac{\partial^{2} c_{h}}{\partial e_{h}^{2}}}$

(6) $\frac{d e_{f}}{d \alpha_{j}}=0$

(7) $\frac{d e_{h}}{d \alpha_{j}}=\frac{-p_{h} \frac{\partial^{2} q_{h}}{\partial e_{h} \partial \alpha_{j}}}{p_{h} \frac{\partial^{2} q_{h}}{\partial e_{h}^{2}}-\frac{\partial^{2} c_{h}}{\partial e_{h}^{2}}}$

The signs of the first two equations determine changes in physician effort for the two stylized patient groups, in response to changes in the HMO population size at the practice level. The second two equations measure the response to changes in the HMO population size at the market level. It is important to distinguish between the two terms 
in the numerators of expression (4) and (5) above. The first term is the extensive margin of the change, and reflects the change in effort that can be attributed to treating more (less) patients due to an increase (decrease) in the size of the relevant population. The second term is the intensive margin, and represents the change in effort level per person, by effort type. Together, these two terms indicate the response of total effort type to changes in practice composition. ${ }^{2}$

For our purposes, it is more interesting to examine the changes in effort intensity by payment type, i.e. the amount of effort per person. These intensity responses are reflected by changes in only the intensive margin discussed above. A formal analysis that restricts its attention to intensive changes is equivalent to an examination of the following comparative statics: $\frac{\partial\left(\frac{e_{f}}{1-\alpha}\right)}{\partial \alpha}$ and $\frac{\partial\left(\frac{e_{h}}{\alpha}\right)}{\partial \alpha}$. This yields the following equations:

(4') $\frac{d\left(\frac{e_{f}}{1-\alpha}\right)}{d \alpha}=\frac{\left[\frac{\partial^{2} c_{f}}{\partial e_{f} \partial \alpha}-p_{f} \frac{\partial^{2} q_{f}}{\partial e_{f} \partial \alpha}\right]}{p_{f} \frac{\partial^{2} q_{f}}{\partial e_{f}^{2}}-\frac{\partial^{2} c_{f}}{\partial e_{f}^{2}}}$
$\left(5^{\prime}\right) \frac{d\left(\frac{e_{h}}{\alpha}\right)}{d \alpha}=\frac{\left[\frac{\partial^{2} c_{h}}{\partial e_{h} \partial \alpha}-\frac{\partial p_{h}}{\partial \alpha} \frac{\partial q_{h}}{\partial e_{h}}-p_{h} \frac{\partial^{2} q_{h}}{\partial e_{h} \partial \alpha_{j}}\right]}{p_{h} \frac{\partial^{2} q_{h}}{\partial e_{h}^{2}}-\frac{\partial^{2} c_{h}}{\partial e_{h}^{2}}}$

\footnotetext{
${ }^{2}$ Expression (6) and (7) do not have an extensive margin because we assume that the individual physician's practice comprises only a small part of the market. Alternatively, we can simply redefine $\alpha_{j}$ as HMO concentration in all other practices in the market region.
} 
Inspection of these equations reveals their equivalence to (4) and (5) without the extensive component. For the remainder of this paper, we shall limit our attention to intensive margin changes, recognizing that the total effort change by payment type is captured by both the intensive and extensive components. For ease of exposition, we will refer to $\frac{\partial\left(\frac{e_{f}}{1-\alpha}\right)}{\partial \alpha}$ and $\frac{\partial\left(\frac{e_{h}}{\alpha}\right)}{\partial \alpha}$ as simply $\frac{\partial e_{f}}{\partial \alpha}$ and $\frac{\partial e_{h}}{\partial \alpha}$, respectively. Equation (6) and (7) remain unchanged.

\section{II.A. Excess Capacity Model}

As indicated earlier, physician's may respond to changes in practice characteristics by changing the quality (or intensity) of services provided to an individual patient through changes in effort. Models of quality choice among monopolistically competitive firms show that firms will choose practice intensity such that the marginal revenue achieved through increased intensity is equal to the marginal cost of producing output at that intensity (Sheshinski, 1976). In the context of physician practice, HMO pricing behavior will mean that the marginal revenue associated with an increase in service intensity for an HMO patient will be smaller than that for an indemnity patient. If, as specified earlier, the marginal cost of production is increasing in effort, physician firms serving HMO patients will choose a lower level of effort than will firms serving indemnity patients. In such a model, the effect of practice characteristics on the treatment of individual patients will depend on the structure of the service intensity production function and the economic rewards for effort. 
In this model, we assume that HMOs seek to pay marginal costs for excess physician capacity (Gold 1995a). If part of the incentive for physicians to participate in managed care plans is to ensure a large client base, excess capacity will likely be larger when HMO concentration is low. Thus, HMO bargaining power will be highest when HMO concentration is low. If bargaining of this type exists, then the fees paid for HMO patients will rise the larger HMO payment is as a share of a physician's practice, i.e. $p_{h}(\alpha)$ and $\frac{\partial p_{h}}{\partial \alpha}>0$. As HMO penetration increases, excess capacity in the practice decreases, and HMOs can no longer extract such low prices from physicians.

The size of the HMO population is assumed to have no effect on the production function of services or their cost functions, i.e. $\frac{\partial^{2} q_{f}}{\partial e_{f} \partial \alpha}=\frac{\partial^{2} c_{f}}{\partial e_{f} \partial \alpha}=\frac{\partial^{2} c_{h}}{\partial e_{h} \partial \alpha}=0$. Inspection of equations (4') and (5') reveal that an increase in the HMO population size has no effect on effort levels to indemnity patients and leads to greater effort levels to managed care patients, i.e. $\frac{d e_{f}}{d \alpha}=0 ; \frac{d e_{h}}{d \alpha}>0$. This latter result is intuitive, as we would expect quantity of services rendered, via effort levels, to increase as fees increase. Given the economic assertion that, ceteris paribus, effort level to managed care patients is lower than that for fee-for-service patients, patterns of care for indemnity and HMO patients will converge as the share of HMO patients in a practice increases.

Proposition 1: In a model where HMOs pay marginal costs for excess physician capacity, treatment intensity of fee-for-service and HMO patients will converge as HMO 
penetration increases within a practice. The effort intensities will converge to the fee-forservice intensity level.

\section{II.B. Demand Inducement Model}

A second model in which physician practice characteristics can affect the treatment of individual patients is one that incorporates demand inducement. If physicians can induce demand for services and income effects are important, then changes in the fees paid by one payer in a multi-payer firm can generate demand inducement for the other payer (McGuire and Pauly, 1991). In the context of alternative financing arrangements, physicians may profit from inducing behavior from indemnity. patients but may not profit from inducing demand from patients paid through HMOs. If HMOs also pay lower rates than indemnity plans, then an increase in the HMO share of a practice will lead to a reduction in physician income. If abstention from demand inducement (or ethical behavior) is a normal good, this increase in HMO share will lead to an increase in demand inducement from fee-for-service patients.

Thus, the production function of services to fee-for-service patients is modeled as

an increasing function of HMO concentration, $q_{f}\left(e_{f}, \alpha\right) ; \frac{\partial q_{f}}{\partial \alpha}>0$; and $\frac{\partial^{2} q_{f}}{\partial e_{f} \partial \alpha}>0 .^{3}$

The size of the HMO population is assumed to have no effect on the cost of service

production or on the price received for services rendered, i.e. $\frac{\partial^{2} c_{f}}{\partial e_{f} \partial \alpha}=\frac{\partial^{2} c_{h}}{\partial e_{h} \partial \alpha}=\frac{\partial p_{h}}{\partial \alpha}=0$.

Inspection of equations (4') and (5') reveal that an increase in the HMO population size 
leads to greater levels of inducement and thus effort to indemnity patients and has no

effect on effort levels to managed care patients, i.e. $\frac{d e_{f}}{d \alpha}>0 ; \frac{d e_{h}}{d \alpha}=0 .{ }^{4}$ Thus, this

framework suggests a divergence in effort intensity by payment type as HMO

concentration increases.

Proposition 2: In a model of demand inducement, treatment intensity of fee-for-service and HMO patients will diverge as HMO penetration increases within a practice. Effort intensity increases for fee-for-service patients, while HMO intensity remains unchanged.

\section{II.C. Fixed Cost Model}

In this model, we assume that there are both fixed and variable of effort production. The fixed cost investment can be thought of as durable equipment or office capacity (intellectual or physical) that cannot vary for the two types of patients. Thus, a physician must assess the needs of their practice, based partly on practice composition, and make an unalterable investment accordingly. More generally, we can think of the fixed cost investment as simply one that is prohibitively costly to change in the short-run. Anticipating our empirical work, it may be reasonable to expect the duration of a patient visit, given the need for advanced scheduling, to be costly to vary by patient and therefore fixed for all patients.

\footnotetext{
${ }^{3}$ In this model, all forms of effort (induced or otherwise) are embodied in our effort variable. This formulation does not alter our results, but simplifies the analysis by eliminating a third choice variable. ${ }^{4}$ It is interesting to note that increasing HMO concentration has an ambiguous effect on the total effort dedicated to indemnity patients. This ambiguity arises because on the extensive margin, the return to indemnity effort is reduced as a result of the smaller fee-for-service patient population size.
} 
Physicians can, however, alter the variable components of effort to each type of patient and thus incur variable costs as well. If the fixed cost investment in the practice is more appropriate for HMO patients, the marginal cost of variable $\mathrm{HMO}$ effort will be quite low and the marginal cost of variable effort to traditional fee-for-service patients will be high. When the fixed cost investment in the practice is more appropriate for feefor-service patients, the opposite is true. Thus, there exists a tension when investing in fixed costs that will be greatly influenced by practice composition. When a practice is predominantly HMO patients, the fixed cost investment will be geared more towards HMO patients, lowering the marginal cost of variable HMO effort and increasing the marginal cost of variable fee-for-service effort. Formally, we represent this relationship between costs and population size as $c_{f}\left(e_{f}, \alpha\right)$ and $c_{h}\left(e_{h}, \alpha\right)$, where $\frac{\partial c_{f}}{\partial \alpha}>0 ; \frac{\partial c_{h}}{\partial \alpha}<0$; $\frac{\partial^{2} c_{f}}{\partial e_{f} \partial \alpha}>0 ;$ and $\frac{\partial^{2} c_{h}}{\partial e_{h} \partial \alpha}<0$

The size of the HMO population is assumed to have no effect on the production function for services or on the price received for services rendered, i.e. $\frac{\partial^{2} q_{f}}{\partial e_{f} \partial \alpha}=\frac{\partial p_{h}}{\partial \alpha}=0$. Thus, inspection of equations (4') and (5') suggest that physician effort for fee-for-service patients is decreasing and physician effort for HMO patients is increasing in the HMO population size, i.e. $\frac{d e_{f}}{d \alpha}<0 ; \frac{d e_{h}}{d \alpha}>0 .$. Like the excess capacity model described earlier, the fixed cost model suggests that practice patterns for HMO and indemnity patients within a practice will converge as the HMO share increases. The

\footnotetext{
${ }^{5}$ We avoid formal modeling of the fixed cost investment, as it complicates the maximization problem and adds little insight. All the impacts of the fixed cost investment are realized through the marginal costs of
} 
fixed cost of production theory also suggests that firms will tend toward more homogeneous payment configurations over time (Glied, 1998).

Proposition 3: In a model with fixed costs of effort type, treatment intensity of fee-forservice and HMO patients will converge as HMO penetration increases within a practice. The effort intensities will converge to some level between the two initial levels.

\section{II.D. Shadow Pricing - Market Patterns Model}

Thus far, we have discussed models that analyze the responsiveness of physician effort to physician practice composition. In addition to these effects on physician behavior, physicians may also respond to characteristics of the practice environment or physician norms (Newhouse and Marquis, 1978). Physicians who treat HMO patients may need to attract them away from traditional fee-for-service practice. If patients are unfamiliar with HMO practice styles, physicians who adopt less intensive styles may find it difficult to retain patients. In this type of quality competition model, the behavior of other local physicians will affect the demand for services from other monopolistically competitive physicians (Glazer and McGuire, 1993). This pattern is similar (at the practice level) to that documented in the 1980 s when competition between HMO and feefor-service insurers apparently led to shadow pricing by HMOs (Feldman and Dowd, 1993).

The degree to which the low-intensity HMO style must be limited depends on the characteristics of other practices in the market, $q_{h}\left(e_{h}, \alpha_{j}\right)$. As the share of HMO patients

effort to the two types of patients. 
in the market increases, physicians will be better able to reduce effort to managed care patients, $\frac{\partial q_{h}}{\partial \alpha_{j}}<0$; and $\frac{\partial^{2} q_{h}}{\partial e_{h} \partial \alpha_{j}}<0$

Inspection of equations (6) and (7) reveal that an increase in the market level HMO population size has no effect on effort levels to indemnity patients and leads to decreased effort levels to managed care patients, i.e. $\frac{d e_{f}}{d \alpha_{j}}=0 ; \frac{d e_{h}}{d \alpha_{j}}<0$. The latter obtains because, as HMO market concentration increases, the threat of losing managed care patients to indemnity plans as a result of lower intensity levels is diminished. At the market level, we will see a divergence in practice style, as increases in HMO market concentration lead all physicians to adopt less-intensive treatment styles for their managed care patients.

Proposition 4: In a model where physicians who treat HMO patients must lure them away from traditional fee-for-service practices, treatment intensity of fee-for-service and HMO patients will diverge as HMO penetration increases within a given market. Effort intensity to HMO patients decreases, while fee-for-service intensity remains unchanged.

\section{II.E. Selection Model}

HMO penetration will affect observed physician behavior quite differently in models where HMOs achieve savings mainly by selecting healthier than average patients. In this case, the observed differences in the intensity of treatment of HMO and fee-forservice patients will reflect differences in underlying health, not physician practice style. 
As HMO penetration increases, HMOs will be forced to enroll less healthy patients and provide them with more intense services, $q_{h}\left(e_{h}, \alpha_{j}\right) ; \frac{\partial q_{h}}{\partial \alpha_{j}}>0$; and $\frac{\partial^{2} q_{h}}{\partial e_{h} \partial \alpha_{j}}>0$.

Inspection of equations (6) and (7) reveal that an increase in the market level HMO population size has no effect on effort levels to indemnity patients and leads to greater effort levels to managed care patients, i.e. $\frac{d e_{f}}{d \alpha_{j}}=0 ; \frac{d e_{h}}{d \alpha_{j}}>0$. This increase in effort intensity is a direct response to a constituency that is less healthy. At the market level, the impact of increased HMO market concentration on the differences in treatment styles by payment type is ambiguous. Whether practice styles converge or diverge will depend on the manner in which patients are allocated across physician groups, and the ensuing health status of each groups' patients. If patients are uniformly allocated across practices, practice styles will converge. If the less healthy patients are concentrated in a handful of practices, styles will diverge. Consistent with this theory, Baker and Corts (1996) find that indemnity premiums increase when the HMO market share rises above $20 \%$.

Proposition 5: In a model where HMOs select healthy patients, the effect on treatment intensities will be ambiguous as $\mathrm{HMO}$ penetration increases within a defined market. If the progressively less healthy HMO patients are allocated uniformly across practices, practice styles will converge. If the allocation of patients is skewed, styles will diverge.

Table 1 summarizes the empirical hypotheses suggested by these various theories of $\mathrm{HMO} /$ fee-for-service. Basic theory suggests that service intensity will be lower for HMO 
patients than for indemnity patients. The effect of an increased share of HMO patients in a practice on intensity will be positive under the excess capacity and the fixed cost model, and zero under the inducement model. The effect of increasing HMO share on the treatment of indemnity patients will be zero under the excess capacity model, positive under an inducement model, and negative in a fixed cost model. The intensity of treatment of indemnity patients will remain constant with an increase in HMO share at the market level under the shadow-pricing model and will increase under the selection model. At the practice level, the excess capacity and fixed cost models imply a convergence in effort levels as HMO penetration increases. The inducement model implies a divergence. At the market level, the shadow pricing model implies a divergence, while the selection model is ambiguous with regard to the difference in effort levels.

\section{Data and Methods}

We test these hypotheses using data from the 1993-1996 National Ambulatory Medical Care Survey (NAMCS), an annual nationally representative survey of randomly sampled physicians in office-based practice. Over 1100 physicians are sampled in each survey year. The NAMCS asks physicians to report characteristics of about 30 randomly sampled visits that take place within a sample week. In total, the surveys include information on about 35,000 patient visits each year, including the expected source of payment for the visit, the geographic location of the visit, and the physician's specialty. The NAMCS payer categories vary slightly across years, in particular, PPO visits are separated from other privately insured non-HMO visits only after 1994. The NAMCS 
data through 1996 do not contain detailed information about the type of payment. For example, the data do not indicate whether a physician received capitation or fee-forservice payment ${ }^{6}$.

The NAMCS data contain considerable detail about patient characteristics and about the treatment provided during a visit. These data include demographic information, up to three diagnoses, services provided at the visit, medications ordered or provided, and duration of visit. Information is available on the geographic location of the visit (region and metropolitan area) and on the physician's specialty.

We code insurance across all years using a consistent metric. The NAMCS permits physicians to code multiple insurance types for a single visit. We omit all visits paid by "unknown" or "other" or "no charge" insurance (these comprise about $8 \%$ of visits in each year). We then rank insurance categories so that each individual falls into only the highest ranked category. From lowest to highest, these categories are: self-pay (which may include traditional indemnity coverage), private insurance, Medicaid, Medicare, PPO (after 1994), HMO. In most of the analysis, we group together self-pay, private insurance, and PPO and call this group TFFS (traditional fee-for-service).

Separate analyses suggest that these three groups closely resemble each other in both patient and visit characteristics.

Next, we use information on all visits to a specific physician and compute the percentage of those visits paid by Medicaid, Medicare, HMOs, and PPOs (after 1994). We omit from the analysis any physician with fewer than 15 visits (observations) in the data. We compute the share of all visits in the physician's market, defined as

\footnotetext{
${ }^{6}$ The 1997 data, which are in several other respects different from the preceding data, do include this information. Using these data, we find that about $34 \%$ of visits paid by HMOs are capitated.
} 
region*metropolitan area* specialty that are paid by each of the payers. Finally, we compute interaction terms for TFFS insurance multiplied by the share of practice in HMO and interaction terms for TFFS insurance multiplied by the share of the marketplace that is HMO.

In all analyses that follow, we control for age, age-squared, female, black, other race, Hispanic, metropolitan area residence, region of residence, sample year and patient diagnosis. We limit the sample for analysis to privately paid visits (but control for the share of visits paid by Medicaid and Medicare), leaving a sample of 68624 visits. It is important to recognize, however, that the extent of actual variation in the data is more limited than suggested by the sample size. The practice share coefficients are identified from information on 2425 distinct practices. The NAMCS includes only limited indicators of the physician's geographic market (region and metropolitan area) so that there are only 111 distinct markets in this analysis.

Standard measures of case mix do not reflect the demands of different types of visits on outpatient visit characteristics. Instead, we code diagnosis using two sets of variables. First, we include a variable for the number of separate diagnoses reported by the physician for the visit. Second, we construct diagnosis categories for each outcome variable. The diagnosis categories divide diagnoses into deciles according to their mean effect on visit characteristics across the entire sample. For example, diagnoses are divided into those with mean visit duration of 12-13 minutes, 14-15 minutes, and so on for the analysis of duration. In some of the analyses, we omit these diagnosis categories in order to assess the potential effects of HMO patient selection on the observed outcomes. 
We examine 4 principal measures of visit intensity: duration of visit, number of tests ordered, number of medications ordered, and whether a return visit was scheduled by the physician. Table 2 presents descriptive statistics for these outcome variables and for the insurance variables that are the focus of this study. Duration is of interest because it is an easily observable measure of visit intensity from the perspective of the patient. Under either TFFS or HMO payment, increasing the duration of visits makes it difficult for physicians to see more patients. Under TFFS payment, however, the physician may be able to bill more for a longer visit. Thus, we expect HMO payment to reduce the duration of visits. Note that we omit from the analysis of duration all visits with duration equal to zero and all visits with duration greater than one hour. In these data, on average visits last 19.8 minutes. Overall visit duration has increased slightly over the 1993-1996 period. HMO visits average nearly one minute shorter than the sample average.

Ordering more tests is one way for physicians to increase the intensity of services — and billings_-without using up much of their own time (McGuire and Pauly, 1991). Again, we expect HMO payment to reduce the number of tests ordered. Unfortunately, the measure of test counts changes between 1994 and 1995 in these data. In regression analyses, year dummies should capture this definitional change. Over the whole period, the number of tests averaged 1.24 per person (about 1.1 per person prior to 1995 and 1.4 per person after 1994). HMO patients receive about $10 \%$ more tests than the sample average. It is plausible that HMO physicians might order less expensive tests than do other doctors. While the NAMCS data do contain information on the type of test, the information is not sufficiently detailed to address this possibility. 
The effect of $\mathrm{HMO}$ payment on medications is less clear. While reducing medication orders may save money, other factors suggest that HMO patients are likely to be prescribed more medications than are indemnity patients. First, HMO patients are more likely to have insurance coverage for pharmaceuticals, so that demand side pressures to reduce intensity will, in this case, be stronger outside HMO practice. Second, providing patients with a prescription may be a way to reduce other more costly interventions. Third, providing patients with prescriptions may reduce their propensity to return for another visit, again saving the physician's time. The average visit in these data included a new prescription order or medication continuation for 1.13 medications. While coding changes did occur between 1994 and 1995, the number of medications ordered or continued has remained quite steady over the four-year period. HMO patients received slightly more medications than the sample average. Again, HMOs may change the types of medication ordered. In particular, they may substitute generic for brand name drugs, or less costly for more costly prescriptions. The data do not allow us to address this possibility.

Finally, asking a patient to return at a specified time is the prototypical example of demand inducement. Physicians paid capitation rates or salaries would prefer that their patients returned seldom, while those paid fee-for-service rates would like them to visit often. A return visit was specified for over $30 \%$ of all visits. The share was slightly higher for $\mathrm{HMO}$ patients. For reasons that are not apparent in the data and may relate to the ordering of questions, the percentage of patients asked to return dropped steeply between 1994 and 1995. 
For each outcome variable, we run successive analyses examining the effects of individual insurance, practice composition, marketplace composition and interaction terms. The fully saturated model is:

(8) $\mathrm{Y}_{\mathrm{i}}=\alpha \mathrm{X}_{\mathrm{i}}+\beta \mathrm{HMO}_{\mathrm{i}}+\Sigma \delta_{\mathrm{j}}$ Share $_{\mathrm{ji}}+\varphi$ Share $_{\mathrm{HMO}, \mathrm{i}} *$ Private $_{\mathrm{j}+} \Sigma \gamma_{\mathrm{j}}$ Market $_{\mathrm{ji}}+$ $\phi$ Market $_{\mathrm{HMO}, \mathrm{i}} *$ Private $_{\mathrm{i}}+\varepsilon_{\mathrm{i}}$

where $X_{i}$ is a vector of individual and practice characteristics (demographic, regional, specialty, and diagnosis related), $\mathrm{j}=$ Medicaid, Medicare, and HMO, Share $\mathrm{j}_{\mathrm{j}}$ is the share of visits in the practice visited by patient i paid by each of these payers, and Market ${ }_{j}$ is the share of visits in the region-metropolitan area-specialty market visited by patient $i$ paid by each of these payers ${ }^{7}$.

We use linear regression for analysis of visit duration, number of tests ordered and the number of medications ordered, and logistic regression for whether a return visit was specified. ${ }^{8}$ In each case, we estimate Huber-White standard errors. Finally, we adjust the standard errors for intra-practice correlation. Initially, we examined the behavior of generalists separately from the behavior of specialists. Coefficients on variables of interest were very similar. We therefore grouped them together (controlling for specialty effects) in the analyses reported here. This adjustment more than doubles the standard error on coefficients associated with individual insurance status.

\footnotetext{
${ }^{7}$ We repeated the analyses using quartiles of HMO penetration at the practice level in place of the continuous variable reported above. The results show a monotonic and approximately linear (in percentage $\mathrm{HMO}$ ) increase in effect sizes from quartile to quartile, suggesting that the linear specification is appropriate.

${ }^{8}$ We repeated the estimates using negative binomial regression for tests and medications ordered. The results were qualitatively similar to those reported here. Since a negative binomial regression is much more computationally costly and more difficult to interpret, we used OLS regression instead.
} 


\section{Results}

The bottom half of Table 2 describes the characteristics of the sample in terms of insurance. About one-third of visits in the sample were paid by HMOs. In total, the sample included information on 2425 distinct physician practices. In the average practice, about $27 \%$ of its patients paid through HMOs. Nearly three-quarters of all doctors had at least one visit paid by an HMO. The average HMO patient visited a practice where just over half of the patients were HMO members. The sample included information on 111 distinct region-metropolitan area-specialty markets. The average market had $23 \%$ of its patient visits paid by HMOs. One-quarter of markets had fewer than $15 \%$ of visits paid by HMOs, while one-quarter had more than $30 \%$ paid by HMOs.

As the HMO data above suggest, practices are relatively segregated. To assess the extent of such segregation, we examine the distribution of patients across types of practices in the NAMCS data. We measure the characteristics of the average practice visited by a TFFS patient and by an HMO patient. We report results in Table 3.

While HMO patients constituted $1 / 3$ of the sample, they made up only $16 \%$ of the patients in the median practice. For each type of insurance, about $2 / 3$ of a physician's practice consisted of patients with the same insurance as the sampled individual. This pattern was slightly more pronounced among generalists than among specialists.

Despite the high degree of segregation, the average non-HMO patient visited a practice that also treated at least some HMO patients. The median fee-for-service, selfpay, or PPO patient visited a practice at which about $4 \%$ of all patients were HMO paid. More than $1 / 4$ of non-HMO private patients visited a practice at which over $20 \%$ of all patients were HMO paid. Similarly, the average HMO patient visited a practice at which 
about $1 / 4$ of all patients were TFFS paid and a further $12 \%$ were publicly paid. Only $10 \%$ of all HMO patients visited practices that treated only HMO patients. These results confirm that there is substantial heterogeneity within physician practices.

\section{IV. a. Visit Characteristics}

Table 4 reports the results of analyses that examine the effect of patient insurance on treatment patterns. We report results for all independent variables (except 15 dummy variables for specialist type). In general, the results for all independent control variables are as expected. Older patients receive treatment of greater intensity than do younger patients. Their visits are longer, they get more tests, and they are asked to return more frequently. Quadratic terms in age are also positive indicating that intensity increases faster at older ages. Women receive somewhat more intensive treatment than do men, and are prescribed significantly more medications. Black patients have shorter visits, more tests, and are less likely to be told to return than are White patients. As expected the year dummies are significant predictors of those variables where definition changes occurred. Visits in the Midwest and south are shorter but include more medications and are more likely to specify a return than visits in the Northeast. Visits in the west are more likely to have a return specified than are those in the Northeast. Visits in metropolitan areas are longer than visits in rural areas. Patients with multiple diagnoses are treated more intensively than those with only one diagnosis. Most specialists have longer and more intensive visits than do generalists, but they are less likely to specify a return visit (not reported in Table).

Turning to the effect of health insurance on intensity, HMO visits appear to be only slightly less intensive than TFFS visits. They average nearly one minute shorter 
duration, but are somewhat more likely to include tests and about equally likely to include medications. HMO patients are (surprisingly) more likely to have a return visit specified than are other patients.

If selection is an important explanation of differences in HMO intensity, we would expect the results of these analyses to be sensitive to exclusion of diagnosis codes. We repeated the analyses excluding the dummy variables for diagnosis intensity. Controlling for diagnosis substantially increases R-squared in these analyses, but it has little or no effect on the HMO coefficient. While this result by no means conclusively indicates that HMOs do not select healthier patients, it does suggest that selection is unlikely to fully explain observed intensity differences.

\section{IV. b. Practice and Market Characteristics}

The next set of analyses control for patient insurance, the composition of insurance in the physician's practice, and the composition of the physician's market. They also include interactions between the practice and market variables and patient visit characteristics. Table 5 reports the results of these analyses.

Practice composition has a large and statistically significant effect on most measures of practice intensity. In each case, F-tests for the group of practice composition variables strongly reject the null hypothesis that practice composition does not affect outcomes.

Market composition effects are much weaker than practice characteristics in explaining patient treatment. Visits are shorter and the number of tests provided is higher in HMO-dominated markets, but these and other market characteristics are never 
significant and always smaller in magnitude than practice composition'. This result is consistent with the findings of Newhouse and Marquis (1978). Market-visit interactions are never large or significant. Controlling for market characteristics has little effect on the effect of individual insurance status on treatment intensity ${ }^{10}$.

Visits in TFFS dominated practices are longer than are those in public-dominated practices (not reported in table) or HMO-dominated practices. The effects are sizable. Moving from a practice without any HMO patients (the $25^{\text {th }}$ percentile of practices) to one with $50 \% \mathrm{HMO}$ patients (slightly above the $75^{\text {th }}$ percentile) reduces visit length by 1.45 minutes, or nearly $8 \%$. Visits in HMO-dominated markets are also shorter than those in other markets (though the result is not significant). Once practice composition is held constant, visits by HMO patients are no longer any shorter than are those of nonHMO patients. ${ }^{11}$ Interaction effects for duration are close to zero, suggesting that visit length is set at the practice level and does not vary by insurance status. The inability of physicians to vary individual visit duration may be partly due to the scheduling difficulties associated with variable visit lengths. These results provide strong evidence for a model of physician behavior with fixed costs in the duration of a visit.

Results for tests ordered, medications prescribed, and return visits are quite similar. Practices with large fractions of Medicare (not reported) or $\mathrm{HMO}$ patients order significantly more tests and prescribe insignificantly more medications than do other

\footnotetext{
${ }^{9}$ Note that when we repeat the analyses and exclude practice characteristics, we find large and significant market effects on duration and tests. This finding suggests that other researchers who find market level effects may, in fact, be observing omitted practice composition effects instead.

${ }^{10}$ In earlier analyses, we also included an interaction between practices and markets. This term was never significant and has little theoretical importance, so it was omitted in further analyses.

${ }^{11}$ One reason for this finding might be a tendency for physicians to report a constant length of visit for all patients. We repeated the analysis omitting all practices where the reported visit length was the same for all patients. The basic results were not affected. For the sample as a whole, over $40 \%$ of the variation in duration is within practices.
} 
practices. Conversely, physicians with Medicaid-dominated practices order significantly fewer tests but order insignificantly more medications (not reported). The effect size for moving from a practice at the $25^{\text {th }}$ percentile to one at the $75^{\text {th }}$ percentile of HMO share is just over $13 \%$ of the mean for tests ordered, $12 \%$ for medications prescribed, and $40 \%$ for return specified. Market effects on tests ordered are positive, but effects on medications are negative and effects on return specified are very small. After controlling for practice and market composition, HMO-paid visits are slightly less likely to include tests $(\mathrm{p}<.05)$, medications, or return visits than are TFFS visits.

Interactions between practice composition and TFFS visit are always the same as the sign of the coefficient on the HMO term and opposite the sign on the HMO-practice variable. Interaction effects for tests $(\mathrm{p}<.01)$ and medications $(\mathrm{p}<.01)$ are nearly equal in magnitude to those on the practice term, while the interaction effect for return visit is about $2 / 3$ as large as the practice term. This pattern suggests that the convergence in treatment intensity occurs because HMO patients are treated more intensively in HMOdominated practices while TFFS patients are treated the same wherever they go. Thus, for tests, medications, and return visits, the empirical evidence supports a model with marginal cost pricing for excess capacity.

IV.c. Simulation Results

To better understand the implications of these coefficients, we simulated treatment intensity outcomes for representative practice and market characteristics. We measured all independent variables at the mean for the generalist physician subsample and tested the effects of varying the HMO practice and market shares from the sample 
$25^{\text {th }}$ percentile (or 0 and 0.1 respectively) to the sample $75^{\text {th }}$ percentile (or 0.5 and 0.4 respectively). Thus, these are in-sample simulations.

We predicted visit treatment intensity for an HMO patient and a non-HMO patient in each practice-market configuration. Table 6 reports the resulting levels of intensity for an $\mathrm{HMO}$ patient and the differences in intensity between an otherwise identical nonHMO and an HMO patient. The table also includes the baseline estimate of the difference in means between HMO and non-HMO patients for each outcome variable.

Turning first to the right-hand panel of results, the most striking finding in the table is that the differences between non-HMO and HMO patients are always greatest in non-HMO practices whether or not in HMO-dominated markets. Even in these situations, the differences are relatively small, always less than $15 \%$ of the variable means. As the share of HMO patients within a practice increases, the differences essentially disappear.

The middle panel of results shows that, with the exception of visit duration, HMO treatment intensity increases as the $\mathrm{HMO}$ share of a practice rises and tends to increase slightly as the HMO share of a marketplace rises.

Looking at the results in more detail, the uncontrolled difference in visit duration for non-HMO and HMO patients is nearly two minutes (1.82 minutes). After including all controls, the effect of moving that patient among practices with different characteristics is quite substantial. HMO visits in HMO-dominated practices and marketplaces are nearly 2 minutes shorter, on average, than HMO visits in low-HMO practices and markets. 
Comparing the effect of being a non-HMO patient to an $\mathrm{HMO}$ patient, in the right-hand panel of results, suggests that in a non-HMO practice within an HMOdominated market, non-HMO patients have somewhat shorter visit duration than HMO patients (note that this difference is less than $1 \%$ of mean duration).

The results for tests, medications, and return are very similar to one another. The initial difference favors $\mathrm{HMO}$ patients relative to non-HMO patients. Once practice and market share are controlled, the point estimate for HMO patients is that treatment is somewhat less intense than among TFFS patients. Moving an HMO patient from a lowHMO practice and market to a high-HMO practice and market increases treatment intensity. The increase for medications is about $8 \%$, for tests it is about $5 \%$, and for return visits it is about 3\%. The differences between HMO and non-HMO patients virtually disappear at the $75^{\text {th }}$ percentile of practice and market share.

\section{Conclusions}

Most physicians treat a variety of patients within their practices and operate within markets where a variety of insurance arrangements exist. While economic theory suggests that, at an individual level, managed care patients will receive less intense treatment than fee-for-service patients, the ability of physicians to modify their behavior when the patient population is heterogeneous may be severely limited. This paper develops several theoretical models of physician effort intensity in a mixed payment environment, both within practice and across practices. When there are fixed costs of effort or when managed care organizations pay marginal costs for excess physician capacity, increases in managed care penetration lead to a convergence in effort levels to 
each patient within a practice. When physicians induce the demand of fee-for-service patients to compensate for low payments from managed care, expansion of managed care at the practice level leads to a divergence in effort levels. At the market level, if physicians compete for patients, effort levels will diverge as managed care grows. If managed care organizations enroll only healthy patients, the expansion of managed care will force them to take on progressively less healthy patients. The impact of this expansion on effort levels will depend on how patients are distributed across practices.

Data from the National Ambulatory Medical Care Survey are employed to test the theoretical hypotheses. We find that financial incentives do matter. Treatment intensity varies between patients, according to the method by which their insurers pay physicians. But variations in treatment intensity depend as much-or more-on the insurance status of other patients treated by the same physician as they do on the insurance status of an individual patient. Market characteristics appear to be less important in determining treatment intensity.

The analysis suggests that physicians do not make up losses in income from their HMO practice by increasing the intensity with which they practice TFFS medicine. Nor does increasing the share of HMO patients in a marketplace appear to change the underlying health characteristics of the practice allowing physicians to provide less intense treatment (since the results are hardly affected by controls for diagnosis). Instead, doctors with large HMO caseloads seem to change the way they do business altogether. Physicians who treat mostly HMO patients appear to adopt a practice style that offers equivalent treatment intensity along most measurable dimensions. In the case of visit duration, strong evidence is provided for a model of physician behavior with fixed costs 
of effort. For tests ordered, medications prescribed, and return visits specified, the evidence supports a model with marginal cost pricing for excess capacity.

These results are consistent with the complaints of doctors who have just begun to take on HMO patients. Physicians seem to have difficulty offering HMO-treatment intensity in non-HMO practices. Visit duration tends to be relatively fixed across patients so that only the other measures of intensity can be varied in these circumstances. Physicians who set up their office to address the incentives associated with non-HMO patients find it more difficult to treat HMO patients.

Contrary to the fears of HMO opponents (or the hopes of advocates), as the share of HMO patients increases, HMO practice intensity comes to look more like non-HMO practice. This, too, is not surprising. From the perspective of patients, physician office visits are the most readily comprehensible part of the medical industry. In a market with third-party payment, patients are unlikely to frequent physicians whom, they believe, treat them with less than optimal intensity.

Nonetheless, the differences in practice patterns do have important implications for our understanding of the physician marketplace. If it is difficult to efficiently respond to HMO incentives in non-HMO practices (and vice versa), practices are likely to become increasingly specialized in the treatment of one or another group of patients. In turn, such segregation is likely to lead to increased vertical integration in the physician services market. 


\section{References}

Baker, Laurence C. and Kenneth S. Corts. "HMO Penetration and the Cost of Health Care: Market Discipline or Market Segmentation." American Economic Association Papers and Proceedings 86(2) May 1996: 389-394.

Feldman, Roger B., Bryan Down, and Gregory Gifford. "The Effect of HMOs on Premiums in Employment-Based Health Plans." Health Services Research 27(6) February 1993: 669-811.

Glazer, Jacob and Thomas G. McGuire "Should Physicians be Permitted to 'Balance Bill' Patients? Journal of Health Economics 11(1993): 239-258.

Glied, Sherry. "Payment heterogeneity, Physician Practice, and Access to Care." American Economic Association Papers and Proceedings 88(2) May 1998: 127-131.

Gold, Marsha, Lyle Nelson, Timothy Lake, Robert Hurley, and Robert Berenson. "Behind the Curve: A Critical Assessment of How Little is Known about Arrangements between Managed Care Plans and Physicians." Medical Care Research and Review 52(3) September 1995a: 307-341.

Gold, Marsha, Robert Hurley, Timothy Lake, T. Ensor, and Robert Berenson. "A National Survey of the Arrangements Managed Care Plans Make with Physicians." New England Journal of Medicine 333(25) Dec.21, 1995b: 1678-83.

Hillman, Alan L., Mark V. Pauly, and Joseph J Kerstein. "How do Financial Incentives Affect Physicians' Clinical Decisions and the Financial Performance of Health Maintenance Organizations?" New England Journal of Medicine 321(2) July 13, 1989: 86-92.

Hillman, Alan, W. Peter Welch, and Mark Pauly. "Contractual arrangements between HMOs and Primary Care Physicians: Three-tiered HMOs and Risk Pools." Medical Care 30(2) 1992: 136-148.

Krohn, Rick and Gregg Broffman. "Utilization Management in a Mixed-Payment Environment" Healthcare Financial Management 52(2) Feb. 1998: 64-67.

Manheim, Larry M. and Joe Feinglass. "Hospital Cost Incentives in a Fragmented Health Care System." Topics in Health Care Financing 21(1), Fall 1994: 24-35.

McGuire, Thomas G. and Mark V. Pauly. "Physician Responses to Fee Changes with Multiple Payers." Journal of Health Economics 10(4) 1991: 385-410.

Miller, Robert H. and Harold S. Luft. "Managed Care Plan Performance Since 1980. A Literature Analysis." Journal of the American Medical Association 271(19), May 18, 1994: 1512-1519. 
Newhouse, Joseph P. and M. Susan Marquis. "The Norms Hypothesis and the Demand for Medical Care." Journal of Human Resources 13, Supplement 1978: 159-182.

Phelps, Charles E. "Diffusion of Information in Medical Care." Journal of Economic Perspectives 6(3) Summer 1992: 23-42.

Remler, Dahlia K., Karen Donelan, Robert J. Blendon, et al. "What do managed Care Plans Do to Affect Care? Results from a Survey of Physicians." Inquiry 34(3) Fall 1997: 196-204

Sheshinski, Eytan. "Price, Quality, and Quantity Regulation in Monopoly Situations." Economica 43 May 1976: 127-137. 
Table 1: Alternative Hypotheses of Physician Response to Increases in HMO Concentration at the Practice and Market Level

\begin{tabular}{|c|c|c|c|c|c|c|}
\hline \multirow[b]{2}{*}{ Model } & \multicolumn{2}{|c|}{$\begin{array}{l}\text { Practice } \\
\text { Level }\end{array}$} & \multicolumn{2}{|c|}{$\begin{array}{l}\text { Market } \\
\text { Level }\end{array}$} & & \\
\hline & $\begin{array}{l}\text { Effort to } \\
\text { FFS } \\
\text { patients }\end{array}$ & $\begin{array}{l}\frac{\text { Effort to }}{\text { HMO }} \\
\text { patients }\end{array}$ & $\begin{array}{l}\text { Effort to } \\
\text { FFS } \\
\text { patients }\end{array}$ & $\begin{array}{l}\text { Effort to } \\
\text { HMO } \\
\text { patients }\end{array}$ & $\begin{array}{l}\text { Practice } \\
\text { Differences }\end{array}$ & $\begin{array}{l}\text { Market } \\
\text { Differences }\end{array}$ \\
\hline Excess capacity & zero & $(+)$ & & & Converge & \\
\hline Demand inducement & $(+)$ & zero & & & Diverge & \\
\hline Fixed costs & $(-)$ & $(+)$ & & & Converge & \\
\hline Shadow pricing & & & zero & $(-)$ & & Diverge \\
\hline Selection model & & & zero & $(+)$ & & $?$ \\
\hline
\end{tabular}




\begin{tabular}{lrrrrrr}
\hline \multicolumn{1}{l}{ Table 2. Descriptive Statistics } & \multicolumn{1}{c}{} \\
\cline { 2 - 7 } & Obs. & Mean & S.D. & HMO Mean & $25^{\text {th }} \%$ & $75^{\text {th }} \%$ \\
Duration & 62534 & 19.76 & 12.27 & 18.54 & 10 & 25 \\
Tests & 68624 & 1.24 & 1.36 & 1.32 & 0 & 2 \\
Medications & 68624 & 1.13 & 1.27 & 1.15 & 0 & 2 \\
Return Spec. & 68624 & 0.31 & 0.46 & 0.33 & & \\
HMO patients & 68624 & 33.05 & & & & \\
Practice Share HMO & 2425 & 0.27 & 0.31 & 0.58 & 0 & 0.45 \\
Market Share HMO & 111 & 0.23 & 0.13 & 0.28 & 0.14 & 0.31 \\
\hline
\end{tabular}

\begin{tabular}{|c|c|c|c|c|c|c|c|}
\hline 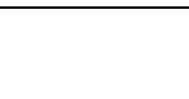 & $\begin{array}{l}\text { Self-Pay/ } \\
\text { Private/PPO }\end{array}$ & Medicaid & Medicare & $\underline{\mathrm{HMO}}$ & $\begin{array}{l}25^{\text {th } \%} \\
\text { HMO }\end{array}$ & $\begin{array}{l}\text { Median } \\
\underline{\text { HMO }}\end{array}$ & $\begin{array}{l}75^{\mathrm{th}_{\mathrm{h}}} \% \\
\mathrm{HMO}\end{array}$ \\
\hline Self pay & 0.64 & 0.07 & 0.17 & 0.12 & & & \\
\hline Private & 0.60 & 0.06 & 0.21 & 0.13 & & & \\
\hline PPO & 0.62 & 0.05 & 0.15 & 0.18 & & & \\
\hline $\begin{array}{l}\text { Self-pay or } \\
\text { Private or } \\
\text { PPO }\end{array}$ & & & & & 0.00 & 0.04 & 0.22 \\
\hline $\mathrm{HMO}$ & 0.27 & 0.04 & 0.11 & 0.58 & 0.33 & 0.58 & 0.86 \\
\hline Total & 0.50 & 0.05 & 0.17 & 0.28 & 0.0 & 0.16 & 0.45 \\
\hline
\end{tabular}




\begin{tabular}{|c|c|c|c|c|}
\hline $\begin{array}{l}\text { Dependent } \\
\text { Variable }\end{array}$ & Duration & Count of Tests & $\begin{array}{l}\text { Medications } \\
\text { Ordered }\end{array}$ & Return Specified \\
\hline Intcpt & $\begin{array}{l}30.81^{*} \\
(424)\end{array}$ & $\begin{array}{c}0.26 \sim \\
011)\end{array}$ & 0.11 & $\begin{array}{l}-1.60^{*} \\
(035)\end{array}$ \\
\hline Age & $\begin{array}{c}0.06^{*} \\
(0.01)\end{array}$ & $\begin{array}{c}0.02 * \\
(0.00)\end{array}$ & $\begin{array}{c}0.00 \\
(0.00)\end{array}$ & $\begin{array}{c}0.01^{*} \\
(0.00)\end{array}$ \\
\hline Agesq & $\begin{array}{c}0.00^{*} \\
(0.00)\end{array}$ & $\begin{array}{c}0.00^{*} \\
(0.00)\end{array}$ & $\begin{array}{c}0.00^{*} \\
(0.00)\end{array}$ & $\begin{array}{c}0.00^{*} \\
(0.00)\end{array}$ \\
\hline Female & $\begin{array}{c}0.03 \\
(0.12)\end{array}$ & $\begin{array}{c}0.02 \\
(0.01)\end{array}$ & $\begin{array}{c}0.09^{*} \\
(0.01)\end{array}$ & $\begin{array}{c}0.03 \\
(0.03)\end{array}$ \\
\hline Hispanic & $\begin{array}{l}-0.04 \\
(0.30)\end{array}$ & $\begin{array}{l}-0.03 \\
(0.03)\end{array}$ & $\begin{array}{c}0.02 \\
(0.04)\end{array}$ & $\begin{array}{l}-0.11 \\
(0.06)\end{array}$ \\
\hline Black & $\begin{array}{l}-0.94^{*} \\
(0.31)\end{array}$ & $\begin{array}{c}0.08 \sim \\
(0.04)\end{array}$ & $\begin{array}{c}0.05 \\
(0.04)\end{array}$ & $\begin{array}{l}-0.23^{*} \\
(0.08)\end{array}$ \\
\hline Other Race & $\begin{array}{l}-0.38 \\
(0.48)\end{array}$ & $\begin{array}{l}-0.04 \\
(0.05)\end{array}$ & $\begin{array}{l}-0.05 \\
(0.04)\end{array}$ & $\begin{array}{l}-0.10 \\
(0.07)\end{array}$ \\
\hline 1994 & $\begin{array}{c}0.15 \\
(0.38)\end{array}$ & $\begin{array}{c}0.00 \\
(0.04)\end{array}$ & $\begin{array}{c}0.02 \\
(0.03)\end{array}$ & $\begin{array}{l}-0.08 \\
(0.07)\end{array}$ \\
\hline 1995 & $\begin{array}{c}0.35 \\
(0.37)\end{array}$ & $\begin{array}{l}0.17^{*} \\
(0.04)\end{array}$ & $\begin{array}{c}0.02 \\
(0.03)\end{array}$ & $\begin{array}{l}-0.59^{*} \\
(0.07)\end{array}$ \\
\hline 1996 & $\begin{array}{c}0.39 \\
(0.40)\end{array}$ & $\begin{array}{l}0.11^{*} \\
(0.04)\end{array}$ & $\begin{array}{c}0.04 \\
(0.04)\end{array}$ & $\begin{array}{l}-0.44^{*} \\
(0.08)\end{array}$ \\
\hline Midw & $\begin{array}{l}-1.89^{*} \\
(0.41)\end{array}$ & $\begin{array}{l}-0.02 \\
(0.04)\end{array}$ & $\begin{array}{c}0.11^{*} \\
(0.04)\end{array}$ & $\begin{array}{c}0.05 \\
(0.09)\end{array}$ \\
\hline South & $\begin{array}{l}-0.48 \\
(0.40)\end{array}$ & $\begin{array}{l}-0.04 \\
(0.04)\end{array}$ & $\begin{array}{c}0.14^{*} \\
(0.03)\end{array}$ & $\begin{array}{c}0.16 \sim \\
(0.08)\end{array}$ \\
\hline West & $\begin{array}{c}0.10 \\
(0.38)\end{array}$ & $\begin{array}{l}-0.02 \\
(0.04)\end{array}$ & $\begin{array}{l}0.08 \sim \\
(0.04)\end{array}$ & $\begin{array}{c}0.14 \\
(0.08)\end{array}$ \\
\hline Metro & $\begin{array}{l}0.75 \sim \\
(0.36)\end{array}$ & $\begin{array}{c}0.05 \\
(0.04)\end{array}$ & $\begin{array}{l}-0.04 \\
(0.03)\end{array}$ & $\begin{array}{l}-0.10 \\
(0.06)\end{array}$ \\
\hline Multi-Diag & $\begin{array}{l}1.23^{*} \\
(0.11)\end{array}$ & $\begin{array}{c}0.21^{*} \\
(0.01)\end{array}$ & $\begin{array}{c}0.34 * \\
(0.01)\end{array}$ & $\begin{array}{l}-0.18^{*} \\
(0.02)\end{array}$ \\
\hline HMO & $\begin{array}{l}-0.89 * \\
(0.22)\end{array}$ & $\begin{array}{c}0.03 \\
(0.02)\end{array}$ & $\begin{array}{c}0.00 \\
(0.02)\end{array}$ & $\begin{array}{c}0.08 \sim \\
(0.04)\end{array}$ \\
\hline 15 Spec.s & Yes & Yes & Yes & Yes \\
\hline Diagnosis codes & Yes & Yes & Yes & Yes \\
\hline R-sq. & 0.222 & 0.31 & 0.196 & 0.115 \\
\hline \#obs: & 62534 & 68624 & 68624 & 68624 \\
\hline $\begin{array}{l}\text { (standard errors } \\
\text { Ambulatory Med } \\
\text { heteroskedasticit } \\
\text { medications are }\end{array}$ & $\begin{array}{l}\text { parentheses } \\
\text { al Care Sur } \\
\text { Results are } \\
\text { S. Return }\end{array}$ & $\begin{array}{l}0.05 \sim, \mathrm{p}<0.01 \\
\text { dard errors are c } \\
\mathrm{d} \text { by NAMCS sa } \\
\text { c regression. }\end{array}$ & $\begin{array}{l}\text { ata are from } 1 \\
\text { cted for clust } \\
\text { e weights. D }\end{array}$ & $\begin{array}{l}996 \text { National } \\
\text { and } \\
\text { n, tests, and }\end{array}$ \\
\hline
\end{tabular}




\begin{tabular}{|c|c|c|c|c|}
\hline $\begin{array}{l}\text { Dependent } \\
\text { Variable }\end{array}$ & Duration & Count of Tests & $\begin{array}{l}\text { Medications } \\
\text { Ordered }\end{array}$ & Return Specified \\
\hline $\begin{array}{l}\text { Practice } \\
\text { HMO \% }\end{array}$ & $\begin{array}{l}-2.89^{*} \\
(0.83)\end{array}$ & $\begin{array}{l}0.32^{*} \\
(0.09)\end{array}$ & $\begin{array}{c}0.27^{*} \\
(0.08)\end{array}$ & $\begin{array}{c}0.25 \\
(0.14)\end{array}$ \\
\hline $\begin{array}{l}\text { Market } \\
\text { HMO \% }\end{array}$ & $\begin{array}{l}-1.72 \\
(2.12)\end{array}$ & $\begin{array}{c}0.25 \\
(0.25)\end{array}$ & $\begin{array}{l}-0.23 \\
(0.20)\end{array}$ & $\begin{array}{c}0.05 \\
(0.44)\end{array}$ \\
\hline HMO & $\begin{array}{c}0.07 \\
(0.51)\end{array}$ & $\begin{array}{l}-0.12 \sim \\
(0.06)\end{array}$ & $\begin{array}{l}-0.09 \\
(0.05)\end{array}$ & $\begin{array}{l}-0.09 \\
(0.11)\end{array}$ \\
\hline FFS*Practice & $\begin{array}{c}0.33 \\
(1.00)\end{array}$ & $\begin{array}{l}-0.30^{*} \\
(0.11)\end{array}$ & $\begin{array}{l}-0.23 \sim \\
(0.10)\end{array}$ & $\begin{array}{l}-0.16 \\
(0.19)\end{array}$ \\
\hline FFS*Market & $\begin{array}{l}-0.21 \\
(1.85)\end{array}$ & $\begin{array}{c}0.08 \\
(0.18)\end{array}$ & $\begin{array}{c}0.14 \\
(0.18)\end{array}$ & $\begin{array}{c}0.00 \\
(0.36)\end{array}$ \\
\hline $\begin{array}{l}\text { R-sq. } \\
\text { \#obs: }\end{array}$ & $\begin{array}{l}0.223 \\
62534\end{array}$ & $\begin{array}{c}0.311 \\
68624\end{array}$ & $\begin{array}{l}0.196 \\
68624\end{array}$ & $\begin{array}{l}0.115 \\
68624\end{array}$ \\
\hline \multicolumn{5}{|c|}{$\begin{array}{l}\text { (standard errors in parentheses with } \mathrm{p}<0.05 \sim, \mathrm{p}<0.01{ }^{*} \text { )Data are from 1993-1996 National } \\
\text { Ambulatory Medical Care Survey. } \\
\text { Analyses also controls for all variables in Tables 3, 6, and } 8 \text { and for diagnosis. Standard errors } \\
\text { are corrected for clustering and heteroskedasticity. Results are weighted by NAMCS sample } \\
\text { weights. Duration, tests, and medications are OLS. Return is logistic regression. }\end{array}$} \\
\hline
\end{tabular}


Table 6. Treatment Intensity under Alternate Practice and Market Configurations

$\underline{\text { HMO Visit }} \quad \frac{\text { Non-HMO - HMO }}{\text { Differences }}$

HMO Practice Share HMO Practice Share

\begin{tabular}{lrllll}
\multicolumn{1}{l}{} & & 0 & 0.5 & 0 & 0.5 \\
\cline { 3 - 6 } & & & & & \\
Visit Duration & & & & & \\
Baseline & 1.82 & & & & \\
HMO Mkt. & $\mid$\begin{tabular}{l|lll}
0.1 \\
Share
\end{tabular} & 14.7 & 13.25 & -0.09 & 0.08 \\
Shar & 14.18 & 12.73 & -0.15 & 0.02
\end{tabular}

Visit Duration

Baseline $\quad 1.82$

Tests Ordered and Performed

Baseline $\quad-0.12$

\begin{tabular}{l|l|lllr} 
HMO Mkt. & 0.1 & 2.12 & 2.28 & 0.13 & -0.02 \\
Share & 0.4 & 2.2 & 2.35 & 0.15 & 0.01
\end{tabular}

Medications

Baseline $\quad-0.02$

\begin{tabular}{l|l|lllr} 
HMO Mkt. & 0.1 & 0.75 & 0.88 & 0.1 & -0.01 \\
Share & 0.4 & 0.68 & 0.82 & 0.15 & 0.02
\end{tabular}

\section{Return Specified}

Baseline $\quad-0.02$

\begin{tabular}{l|l|llll} 
HMO Mkt. & 0.1 & 0.76 & 0.78 & 0.02 & 0 \\
Share & 0.4 & 0.76 & 0.78 & 0.02 & 0.01 \\
\hline
\end{tabular}

Simulations based on results in Table 5. Simulations constructed at mean of all independent variables and for a visit to a generalist physician. 